\title{
A comprehensive investigation of the demographics, treatments, comorbidities, and disease burden of chronic rhinosinusitis with nasal polyposis patients: a descriptive analysis
}

\author{
Qiuliang Zhao ${ }^{1,2}$, Li Yu ${ }^{1,2}$, Peng Jin ${ }^{3}$, Wen Ma ${ }^{1,2}$, Shuonan Duan ${ }^{1,2}$, Hang Luo ${ }^{4}$ \\ ${ }^{1}$ Department of Otolaryngology, Jinan Central Hospital, Cheeloo College of Medicine, Shandong University, Jinan, China; ${ }^{2}$ Department of \\ Otolaryngology, Central Hospital Affiliated to Shandong First Medical University, Jinan, China; ${ }^{3}$ Department of Otolaryngology, The Second \\ Hospital, Cheeloo College of Medicine, Shandong University, Jinan, China; ${ }^{4}$ Shanghai Palan DataRx Co., Ltd., Shanghai, China \\ Contributions: (I) Conception and design: Q Zhao, L Yu; (II) Administrative support: Q Zhao, L Yu; (III) Provision of study materials or patients: \\ P Jin, W Ma, S Duan; (IV) Collection and assembly of data: P Jin, W Ma, S Duan; (V) Data analysis and interpretation: H Luo; (VI) Manuscript \\ writing: All authors; (VII) Final approval of manuscript: All authors. \\ Correspondence to: Qiuliang Zhao. Department of Otolaryngology, Jinan Central Hospital, Cheeloo College of Medicine, Shandong \\ University, Jinan, China; Department of Otolaryngology, Central Hospital Affiliated to Shandong First Medical University, Jinan, China. \\ Email: zhaoqiuliang2004@163.com.
}

Background: Chronic rhinosinusitis with nasal polyposis (CRSwNP) is a frequently diagnosed chronic disease that has been widely recognized as a significant economic strain on society. Recently, concern about the rising prevalence of eosinophilia in CRSwNP has attracted research interest. A comprehensive understanding of the characteristics and disease burden of CRSwNP patients may contribute to improved management of these patients.

Methods: We conducted a multi-center retrospective observational study based on real-world data. Patients were filtered into three groups: CRSwNP overall group, CRSwNP surgical group, and CRSwNP patients who had a relapse after surgeries. Furthermore, we used laboratory test results of blood eosinophil percentage (EOS\%) as an indicator of eosinophilia. The comorbidities and medications of patients in the high and low EOS\% groups were compared. Disease burden was measured from two aspects: direct costs and loss of working days.

Results: A total of 1,724 CRSwNP patients were eligible, 527 of which were filtered into the surgical groups. Only 16 patients in this study were found to have a relapse. The mean ages of the CRSwNP nonsurgical, CRSwNP surgical, and CRSwNP relapse groups were 46, 47, and 52.5 years old, respectively. Most patients sought treatment in the otolaryngology department. Among all three groups, the most prevalent comorbidities were allergic rhinitis and asthma. The most prescribed drug was intranasal/oral corticosteroids. The direct costs per person/year for the non-surgical group, surgical group, and relapse group were $¥ 188.60$, $¥ 15,190.00$, and $¥ 14,160.00$, respectively. The loss of working days per person/year for the non-surgical group, surgical group, and relapse group was 10.41, 24.40, and 21.65 days, respectively.

Conclusions: CRSwNP is a disease of middle age. It is frequently associated with asthma and allergic rhinitis. Eosinophilia was found to have a considerate influence on patients' treatment patterns. Based on available data, we noted that patients in the high EOS\% group were more likely to have asthma and allergic rhinitis. Intranasal/oral corticosteroids were the most frequently used drug for patients with CRSwNP, while a smaller proportion of patients in the high EOS\% group used intranasal/oral corticosteroids. The disease burden of CRSwNP is posing significant challenges to both patients and society.

Keywords: Chronic rhinosinusitis with nasal polyposis (CRSwNP); endoscopic sinus surgeries (ESS); relapse; disease burden 
Submitted Dec 17, 2021. Accepted for publication Jan 14, 2022.

doi: 10.21037/atm-22-65

View this article at: https://dx.doi.org/10.21037/atm-22-65

\section{Introduction}

Chronic rhinosinusitis (CRS) is an inflammatory condition of the paranasal sinuses that involves two clinically distinct entities: chronic rhinosinusitis without nasal polyposis (CRSsNP) and chronic rhinosinusitis with nasal polyposis (CRSwNP) (1). A study conducted in China in 2012 showed that CRS affects approximately $8 \%$ of the Chinese population (2). CRSwNP is a clinical phenotype of CRS characterized by persistent polypoid inflammation of the sinonasal mucosa. The symptoms include anterior or posterior rhinorrhea, nasal congestion, hyposmia, and/ or facial pain that can last for more than 12 weeks (3). CRSwNP can be further divided into eosinophilic CRSwNP (ECRSwNP) and non-eosinophilic CRSwNP (NECRSwNP), depending on the histology of nasal polyps (4). It has been reported that the presence of tissue eosinophilia in CRSwNP is frequently related to a higher polyp recurrence rate (5). Recent study has shown that the incidence of ECRSwNP has increased remarkably in the past 11 years in China (6), drawing increasing attention.

CRSwNP is not a life-threatening disease, yet it is associated with considerable morbidity and decreased quality of life. In a large retrospective study that evaluated 446,480 CRS patients diagnosed between 2001 and 2010, those who had CRSwNP had a significantly higher premorbid prevalence of acute rhinosinusitis, allergic rhinitis, chronic rhinitis, asthma, gastroesophageal reflux disease, and sleep apnea (7). Medical management of CRSwNP focuses on tissue inflammation control and possible bacterial infection treatment. According to the 2013 US guidelines, both topical corticosteroids and nasal saline irrigation are recommended as initial treatments for diagnosed patients $(8,9)$. Polypectomy and functional endoscopic sinus surgeries (ESS) are common options if medical treatment fails to control symptoms. Personalized endotype-driven treatment is one of the cornerstones of precision medicine. CRSwNP patients with Th2-biased inflammatory responses, eosinophilic polyps, and high serum IgE levels might benefit from the use of biologics (10). It is evident that biologicals targeting type 2 inflammation are an option for the treatment of patients with CRSwNP and related comorbidities (11).

CRSwNP poses critical economic challenges to society. In
2019, Bhattacharyya et al. discovered that the average annual cost for each CRSwNP patient is as high as $\$ 18,964$ (12). Moreover, studies have shown that not all CRSwNP patients will be cured or obtain control of their symptoms, even with maximal medical management or surgical intervention $(13,14)$. This fact contributes to extensive disease burden and medical resource utilization.

Although there is abundant literature on the microbiology, pathophysiology, diagnosis, and treatment of CRSwNP, most population-based epidemiological research was conducted through surveys, interviews, or self-reported records. There is limited research on the demographics and disease burden of CRSwNP based on real-world data. Despite the recalcitrant nature of the disease and the associated high symptom burden, an under-recognized clinical, humanistic, and economic burden also existed in the CRSwNP patients. Existing medical and surgical interventions, may be associated with recurrence and potential side effects and risks. Patients with CRSwNP often have comorbid asthma and/or nonsteroidal anti-inflammatory drug-exacerbated respiratory disease (NSAID-ERD) (15). The associations between ECRSwNP and related treatment patterns remain poorly understood. In this study, we used data from January $1^{\text {st }}, 2013$ to June $30^{\text {th }}, 2019$ to determine the treatment and disease burden status quo. We conducted a multi-center retrospective observational study was performed based on real-world data derived from electronic medical records in the mainland China. Our primary objectives are to: (I) explore the demographic characteristics of CRSwNP patients; (II) investigate the comorbidity status and medications of CRSwNP patients; (III) assess the impact and disease burden of eosinophilia in CRSwNP on patients' comorbidities and medications; and (IV) determine the disease burden of CRSwNP in mainland China. We present the following article in accordance with the STROBE reporting checklist (available at https://atm.amegroups. com/article/view/10.21037/atm-22-65/rc).

\section{Methods}

\section{Study design}

A multi-center retrospective observational study was 
performed based on real-world data derived from electronic medical records (EMRs). In this study, the patient population, namely the CRSwNP patient group, was filtered into three subgroups: the CRSwNP group, the CRSwNP surgical group, and the CRSwNP relapse group. In every subgroup, we investigated patients' demographic characteristics including age and sex at baseline, comorbidity status, and prescription records. Also, we presented the disease burden of the surgical group, non-surgical group, and relapse group from two aspects: direct disease cost per person/per time and annual loss of working days. Limited by the data source we used, blood eosinophilia was used as a surrogate marker for tissue eosinophilic inflammation. We adopted a blood eosinophil percentage (EOS\%) of $3.05 \%$ proposed by $\mathrm{Hu}$ et al. as a cutoff value (16). Based on the patients' blood EOS\% laboratory test results, each subgroup was divided into a high EOS\% group and low EOS\% group. Patient's comorbidity and medication patterns were compared in these two groups.

The baseline was set as follows: the date when a patient's first CRSwNP diagnosis was recorded in the database between January $1^{\text {st }}, 2013$ and June $30^{\text {th }}, 2019$.

This study was approved by the Ethics Committee of Jinan Central Hospital (approval number: 2020-032-02), and patient consents were waived due to retrospective study design. All procedures in this study involving human participants were conducted in accordance with the Declaration of Helsinki (as revised in 2013).

\section{Data source}

The data we collected was from the Jinan Health Medical Big Data Platform which owned by Jinan Health Commission. The platform integrates the medical and health data of the vast majority of medical institutions at all levels in Jinan City, Shandong Province. In this study, seven general or specialized hospitals which covered the information of most CRSwNP patients during the period from January $1^{\text {st }}$, 2013 to June $30^{\text {th }}, 2019$ in the platform were included. The following information was covered in the database:

(I) Demographic and visiting information, including date of birth, sex, diagnosis date and time, admission type, department, insurance type;

(II) Diagnosis information, including CRSwNPrelated diagnosis, comorbidity-related diagnosis, postoperative complications, diagnosis type, diagnosis number;

(III) Laboratory test results, including peripheral blood
EOS\%;

(IV) Imaging examination records, including paranasal sinus CT/MRI;

(V) Surgical information, including surgical type, surgical date and time;

(VI) Prescription records, including drug generic names, prescription date and time, drug usage and dose;

(VII) Costs, including materials, tests, examinations, ward, nursing, diagnosis and treatment, surgical, medication, anesthesia, and other costs;

(VIII) Other clinical information, including group consultation records, if applicable.

\section{Study population}

\section{Inclusion criteria}

Patients were eligible for inclusion in the CRSwNP group if they were found to have been diagnosed with CRSwNP between January $1^{\text {st }}, 2013$ to June $30^{\text {th }}, 2019$ in the database. To identify CRSwNP patients, we filtered diagnosis variables by the following keywords: "chronic rhinosinusitis with nasal polyposis", "nasal polyp", "CRSwNP", or by ICD-10 code 'J33.900'.

Patients were eligible for inclusion in the CRSwNP surgical group if they were diagnosed with CRSwNP and had records of being admitted for surgeries at the otolaryngology department between January $1^{\text {st }}, 2013$ to June $30^{\text {th }}, 2019$.

Patients were included in the CRSwNP non-surgical group if they were diagnosed with CRSwNP and no records of being admitted for surgeries between January $1^{\text {st }}, 2013$ to June $30^{\text {th }}, 2019$ were found in the database.

The CRSwNP relapse group was defined as patients who were diagnosed with CRSwNP, admitted for surgeries at the otolaryngology department, and then diagnosed with CRSwNP again 6 months after the surgery date.

\section{Exclusion criteria}

We excluded patients who were diagnosed with choanal polyp, those whose baseline diagnosis was missing, and those lacking personal information such as date of birth.

\section{Main outcomes}

In this study, we presented the following outcomes and corresponding analysis:

(I) Patient demographic characteristics: including age, age group $(0-14,15-34,35-59$, over 59$)$, sex 


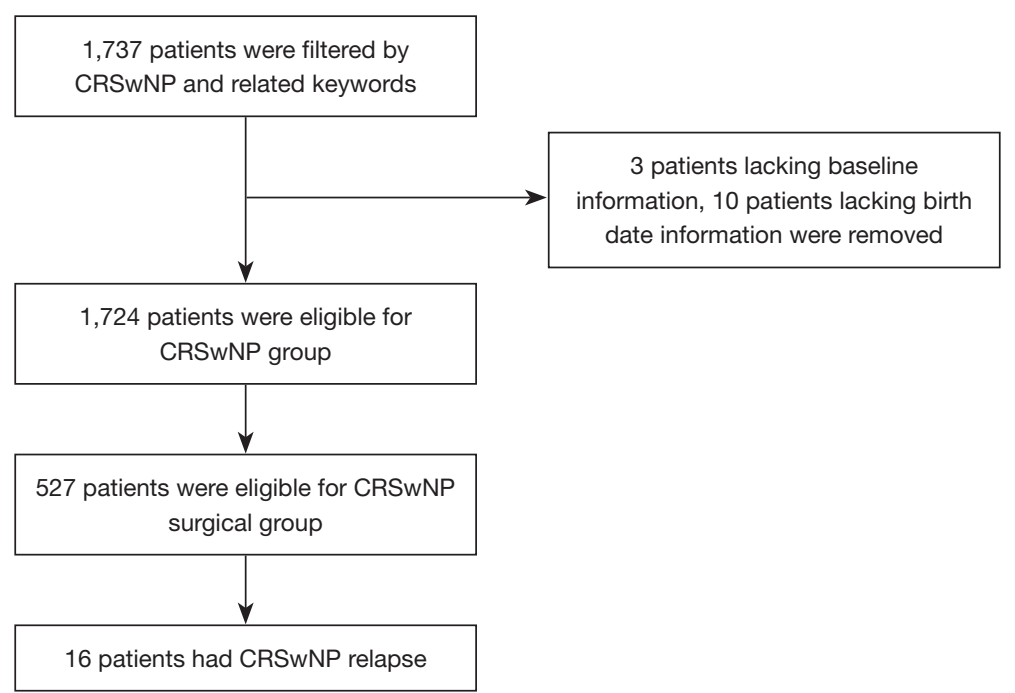

Figure 1 Schematic flowchart for data screening. CRSwNP, chronic rhinosinusitis with nasal polyposis.

distribution, and visited department information.

(II) Patients' comorbidity status: observed comorbidities including asthma, chronic obstructive pulmonary disease (COPD), eczematous dermatitis, acute rhinitis, anaphylactic rhinitis, and somnipathy.

(III) Prescriptions: including intranasal/oral glucocorticoids, antihistamines and antileukotrienes, decongestant, macrolides antibiotics, normal saline (for rinsing), and traditional Chinese medicine.

(IV) Disease burden was expressed from two different aspects-annual direct economic cost per person and per time, and annual loss of working days per person. Direct disease cost was defined as the sum of expenditure recorded in the database. Annual loss of working days was defined as follows: in every patient year, the number of days that a patient spent in hospital, including outpatient visit and inpatient visit. It was calculated by the following formula:

Annual loss of working days $=$ [outpatient visit $x$ 1 day/time + hospitalization days (if applicable)]/ duration $=[$ outpatient visit $\times 1$ day/time $+($ discharge date and time - admission date and time)]/duration

A patient's duration was calculated by: the date of latest CRSwNP related diagnosis in the database-baseline date.

\section{Statistical analysis}

We designed this study to provide a comprehensive and reliable descriptive statistical analysis based on real- world data. The continuous variables are expressed in the form of number $(\mathrm{N})$, mean, standard deviation, median, minimum value, maximum value, and low/upper quartile, as appropriate. Time/period measurements were calculated using the following formula: time (year) $=$ (end date and time - start date and time)/365.25. Besides the patients who did not have date of birth or baseline diagnosis information, we did not find any missing data in any variable among the observed patients. In addition, we did not find any clinical outlier in the laboratory test results in this study. All the data analyses were conducted with the R statistical package v.2.13.1 (R Foundation for Statistical Computing, Vienna, Austria).

\section{Results}

\section{Demographic characteristics}

The data screening process is shown in Figure 1. A total of 1,724 patients met the selection criteria for CRSwNP, among which 527 underwent ESS. Six months after ESS, 16 patients were diagnosed with CRSwNP again.

The demographic characteristics of CRSwNP patients are shown in Table 1. All 3 groups shared similar patterns of sex distribution. There were more males than females in CRSwNP, CRSwNP surgical and CRSwNP relapse group (65.2\% versus $34.8 \%, 68.9 \%$ versus $31.1 \%$, and $68.7 \%$ versus $31.3 \%$ ). The mean age for CRSwNP, CRSwNP surgical and CRSwNP relapse group was 46, 47, and 52.5 years old, respectively. The majority of patients in all 3 subgroups were aged between 35 and 59 years old at 
Table 1 The demographic characteristics of CRSwNP patients

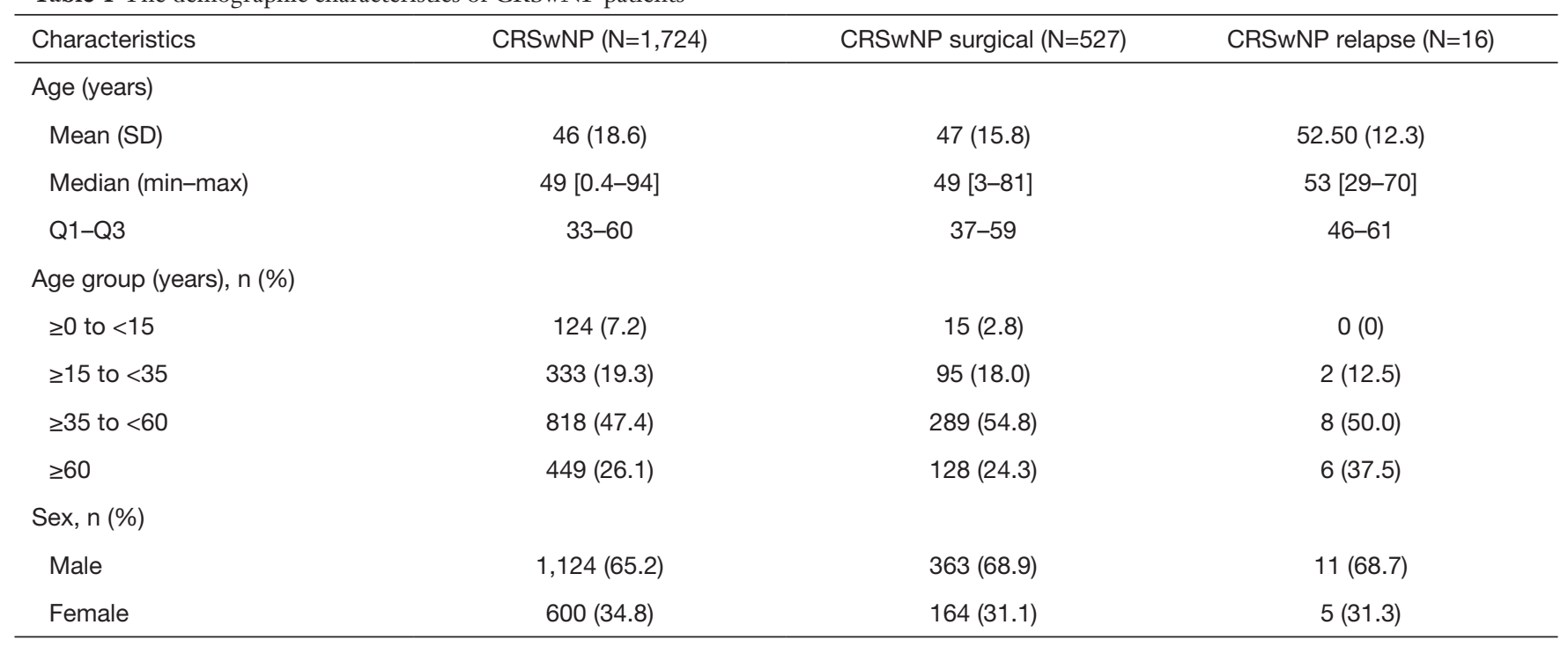

CRSwNP, chronic rhinosinusitis with nasal polyposis; SD, standard deviation; Q1, first quartile; Q3, third quartile.

Table 2 Departments for CRSwNP patients at baseline, follow-up, and after surgery

\begin{tabular}{lccc}
\hline Department & Baseline diagnosis, N (\%) & Follow-up visit, N (\%) & After surgery, N (\%) \\
\hline Otolaryngology & $1,519(88.1)$ & $1,152(81.8)$ & $70(58.3)$ \\
Other internal & $80(4.6)$ & $314(22.3)$ & $30(25.0)$ \\
Neurology & $28(1.6)$ & $93(6.6)$ & $15(12.5)$ \\
Surgery & $27(1.6)$ & $138(9.8)$ & $24(20.0)$ \\
Others* & $26(1.5)$ & $97(6.9)$ & $5(4.1)$ \\
Respiratory & $25(1.5)$ & $106(7.5)$ & $9(7.5)$ \\
Gastroenterology & $9(0.5)$ & $56(4.0)$ & $9(7.5)$ \\
TCM & $5(0.3)$ & $63(4.5)$ & $5(4.1)$ \\
Dermatology & $4(0.2)$ & $60(4.3)$ & $2(1.7)$ \\
Ophthalmology & $1(0.1)$ & $36(2.6)$ & $4(3.3)$ \\
Stomatology & $0(0.0)$ & $22(1.6)$ & $2(1.7)$ \\
Total & 1,724 & 1,409 & 120 \\
\hline
\end{tabular}

*, 'Others' includes anesthesiology department, gynecology, and obstetrics, among others. TCM stands for traditional Chinese medicine department. CRSwNP, chronic rhinosinusitis with nasal polyposis.

baseline (47.4\% for CRSwNP group, 54.8\% for CRSwNP surgical group, and $50.0 \%$ for CRSwNP relapse group).

\section{Department analysis}

We investigated the medical departments that patients presented to at baseline, follow-up visit, and after surgeries (Table 2). It was found that at baseline diagnosis, of all the
1,724 CRSwNP patients included in this study, $88.1 \%$ went to the otolaryngology department at baseline diagnosis, $4.6 \%$ went to other internal departments, and $1.6 \%$ went to the neurology department. Among all the included CRSwNP patients, 1,409 patients had all-time follow-up visits after baseline diagnosis. The majority of them (81.8\%) went to the otolaryngology department for treatment, while $22.3 \%$ of them also went to other internal departments 
Table 3 Comorbidity status for patients with CRSwNP

\begin{tabular}{|c|c|c|c|c|c|c|c|c|c|}
\hline Comorbidity status & \multicolumn{3}{|c|}{ CRSwNP $(\mathrm{N}=1,724)$} & \multicolumn{3}{|c|}{ CRSwNP surgical $(\mathrm{N}=527)$} & \multicolumn{3}{|c|}{ Relapse after surgeries $(\mathrm{N}=16)$} \\
\hline Asthma & $99(5.7 \%)$ & $5(6.7 \%)$ & $3(1.4 \%)$ & $19(0.036)$ & $2(3.3 \%)$ & $2(1.1 \%)$ & $1(6.3 \%)$ & NA & NA \\
\hline Dermatitis/eczema & $75(4.4 \%)$ & $2(2.7 \%)$ & $0(0)$ & $6(0.011)$ & $0(0)$ & $0(0)$ & $1(6.3 \%)$ & & \\
\hline Acute rhinitis & $36(2.1 \%)$ & $1(1.3 \%)$ & $4(1.9 \%)$ & $2(0.004)$ & $0(0)$ & $1(0.6 \%)$ & $1(6.3 \%)$ & & \\
\hline Allergic rhinitis & $170(9.9 \%)$ & $4(5.3 \%)$ & $1(0.5 \%)$ & $29(0.055)$ & $2(3.3 \%)$ & $1(0.6 \%)$ & $3(18.9 \%)$ & & \\
\hline Somnipathy & $44(2.6 \%)$ & $1(1.3 \%)$ & $1(0.5 \%)$ & $3(0.005)$ & $0(0)$ & $0(0)$ & $0(0)$ & & \\
\hline
\end{tabular}

CRSwNP, chronic rhinosinusitis with nasal polyposis; EOS\%, eosinophil percentage; NA, not applicable; COPD, chronic obstructive pulmonary disease.

and $9.8 \%$ went to the surgery department. After ESS, 120 patients out of 527 had follow-up visits, and $58.3 \%$ of them went to the otolaryngology department, $25.0 \%$ of them went to other internal departments, and 20.0\% went to the surgery department.

\section{Comorbidities}

We divided CRSwNP patients into two groups, namely the EOS\% laboratory result $\geq 3.05 \%$ and $<3.05 \%$ groups, with 75 and 215 patients in each subgroup, respectively. For the 527 patients who had ESS, 60 of them had an EOS\% laboratory result $\geq 3.05 \%$ and 174 had a result $<3.05 \%$. Overall, the most prevalent comorbidity found in the study population of CRSwNP patients was allergic rhinitis (9.9\%), followed by asthma (5.7\%) and eczematous dermatitis (4.4\%). For those who were in the high EOS\% group, the top 3 prevalent comorbidities were asthma, allergic rhinitis, and COPD, and the top comorbidities for the low EOS\% group were acute rhinitis and asthma. A similar pattern was found in patients who had ESS. Only 6 patients had EOS\% laboratory results in the CRSwNP relapse group and none of them were found to be diagnosed with the observed comorbidities (Table 3).

\section{Prescriptions}

We investigated the prescribing records in the database (Table 4) and found that besides normal saline, intranasal/ oral corticosteroids were mostly prescribed in each subgroup. Of all 1,434 CRSwNP patients who had prescribing records, $46.2 \%$ were prescribed intranasal/ oral corticosteroids. For those who had ESS, $81.4 \%$ were prescribed intranasal/oral corticosteroids before surgeries and even more (82.5\%) were prescribed after. All 16 patients who suffered a CRSwNP relapse after surgeries had to use intranasal/oral corticosteroids. Notably, in the CRSwNP group, fewer patients with higher EOS\% results were prescribed intranasal/oral corticosteroids.

Antihistamine and antileukotrienes were the second most frequently prescribed drug combination. A total of 313 out of 1,434 patients with CRSwNP had them in their treatment routine. For patients who had ESS, $14.1 \%$ and $13.1 \%$ of those who had prescribing records had antihistamine and antileukotrienes before and after surgeries, respectively. Furthermore, all 469 CRSwNP surgical patients with prescribing records were prescribed normal saline for nasal rinsing before surgeries, while after surgeries, only $34.9 \%$ prescribed normal saline.

\section{Disease burden}

We calculated and compared the direct economic burden of the non-surgical group, surgical group, and relapse group (Table 5). Data is expressed as median (Q1-Q3). Of all investigated patients, 668 of those who did not have ESS had cost information, 396 patients in the surgical group had cost information, and 13 relapse patients had cost information. The median costs per person in the nonsurgical group, surgical group, and relapse group were $¥ 188.60$, $¥ 15,190.00$, and $¥ 14,160.00$, respectively. The median costs per time in the non-surgical group, surgical group, and relapse group were $¥ 174.00, ¥ 13,030.00$, and $¥ 12,460.00$, respectively. 
Table 4 Prescribing analysis for the CRSwNP, CRSwNP surgical, and relapse groups

\begin{tabular}{|c|c|c|c|c|c|c|c|c|}
\hline Prescriptions & \multicolumn{3}{|c|}{ CRSwNP $(\mathrm{N}=1,434)$} & \multicolumn{2}{|c|}{ CRSwNP surgical $(N=576)$} & \multicolumn{3}{|c|}{ CRSwNP relapse $(\mathrm{N}=16)$} \\
\hline Intranasal/OCS & $663(46.2 \%)$ & $51(75.0 \%)$ & $174(88.3 \%)$ & $382(81.4 \%)$ & $421(82.5 \%)$ & $13(81.2 \%)$ & $3(100 \%)$ & $3(100 \%)$ \\
\hline $\begin{array}{l}\text { Antihistamine/anti- } \\
\text { leukotrienes }\end{array}$ & $313(21.8 \%)$ & $0(0)$ & $0(0)$ & $70(14.1 \%)$ & $74(13.1 \%)$ & $3(18.8 \%)$ & $0(0)$ & $0(0)$ \\
\hline Decongestant & $23(1.6 \%)$ & $0(0)$ & $0(0)$ & $0(0)$ & $0(0)$ & $0(0)$ & $0(0)$ & $0(0)$ \\
\hline Macrolide antibiotics & $122(8.5 \%)$ & $0(0)$ & $0(0)$ & $41(8.7 \%)$ & $46(7.8 \%)$ & $5(31.2 \%)$ & $0(0)$ & $0(0)$ \\
\hline $\begin{array}{l}\text { Normal saline (for } \\
\text { rinsing) }\end{array}$ & $598(41.7 \%)$ & $66(98.5 \%)$ & 197 (100\%) & $469(100 \%)$ & 503 (34.9\%) & $16(100 \%)$ & $3(100 \%)$ & $3(100 \%)$ \\
\hline
\end{tabular}

CRSwNP, chronic rhinosinusitis with nasal polyposis; EOS\%, eosinophil percentage; OCS, oral corticosteroids.

Table 5 Direct disease burden

\begin{tabular}{lcc}
\hline Total cost median (Q1-Q3) & Per person (Yuan) & Per time (Yuan) \\
\hline Non-surgical group $(\mathrm{N}=668)$ & $188.60(88.03-570.50)$ & $174.00(79.40-530.80)$ \\
Surgical group $(\mathrm{N}=396)$ & $15,190.00(11,330.00-15,420.00)$ & $13,030.00(9,012.00-18,890.00)$ \\
Relapse group $(\mathrm{N}=13)$ & $14,160.00(11,330.00-15,410.00)$ & $12,460.00(8,370.00-20,080.00)$ \\
\hline
\end{tabular}

Q1, first quartile; Q3, third quartile.

Table 6 Indirect disease burden-loss of working days

\begin{tabular}{lc}
\hline Indirect burden & $\begin{array}{c}\text { Loss of working days (days per } \\
\text { person) }\end{array}$ \\
\hline Non-surgical group $(\mathrm{N}=668)$ & 10.41 \\
Surgical group $(\mathrm{N}=396)$ & 24.40 \\
Relapse group $(\mathrm{N}=13)$ & 21.65 \\
\hline
\end{tabular}

We used annual loss of working days as an indicator to represent indirect disease burden of CRSwNP. For the non-surgical group, surgical group, and relapse group, the mean loss of working days per person was 10.41, 24.40, and 21.65 days, respectively (Table 6).

\section{Discussion}

To the best of our knowledge, this is the first study that explores the demographics, comorbidities, prescriptions, and disease burden of CRSwNP patients using real-world data in mainland China. Also, this is the first study to use blood EOS\% as an indicator to compare differences of patients' comorbidities and prescriptions.

Among all 1,724 CRSwNP patients included in this study, 527 had ESS and 16 underwent a relapse after ESS. The mean age of all CRSwNP patients was 46 years old. The majority of patients were between 35 and 59 years old at baseline diagnosis. In a study by Grigoreas et al., the mean age of their study population was 42 years old, typically ranging from 40 to 60 years old (17). We found that males are more likely to have CRSwNP than females. However, a study in 2016 by Stevens et al. reported that females with CRSwNP had more severe symptoms than males (3). This remains to be further investigated. The mean age of those who had a relapse was 52.50 years old. No one under 15 years old had a relapse, indicating that failure of controlling CRSwNP symptoms and relapse might be associated with older age.

Allergic rhinitis was the most prevalent comorbidity found in all three subgroups, followed by asthma. This finding is in line with Tan et al.'s work in 2013. In their study, a cohort of 595 CRSwNP patients were evaluated. 
However, $12.8 \%$ of their study cohort had allergic rhinitis, while in our study, the prevalence was $9.9 \%$ (7). They also found that CRSwNP is strongly associated with sleep disorders. Very few patients in our study had somnipathy as a comorbidity. The difference might be caused by the size of the study population and ethnicity. Among CRSwNP patients whose $\mathrm{EOS} \% \geq 3.05 \%$, asthma was the most prevalent comorbidity (6.7\%), while for those with EOS $\%<3.05 \%$, acute rhinitis was the most prevalent comorbidity (1.9\%).

We investigated the treatment patterns of CRSwNP patients from two aspects: visited departments and medications. Among the 1,724 included CRSwNP patients, 1,409 had follow-up visit records, while among the 527 patients who had ESS, 120 had follow-up visits after surgeries. The majority of patients presented to the otolaryngology department for treatment both at first diagnosis and follow-up visit. For patients who had ESS, $58.3 \%$ presented to the otolaryngology department after surgeries.

For CRSwNP patients, the most commonly used drugs were intranasal/oral corticosteroids. It is well known that corticosteroids can reduce polyp size and improve symptoms (18). However, prescriptions should always be administered cautiously given their association with serious systemic side effects (19). Antibiotics may be useful in treating infectious exacerbations of CRSwNP, but evidence of clinically significant efficacy (i.e., polyp shrinkage) in large randomized trials is lacking (20). Intranasal/ oral corticosteroids are less commonly prescribed in high EOS\% patients than in low EOS\% patients. This might be explained by a recent study which found that ECRSwNP patients have a lower tolerance for intranasal/ oral corticosteroids (21). Thus, personalized medication is necessary for patients who have different eosinophil levels. Effective treatment remains a big challenge.

The median costs per patient for the non-surgical group, surgical group, and relapse group were $¥ 188.60, ¥ 15,190.00$, and $¥ 14,160.00$, respectively. Evidently, economic pressure on patients who had received ESS was markedly larger than those who did not. However, patients who had a relapse typically spent less. This is due to the small sample size of the relapse group who also had cost records. The loss of working days of the non-surgical group, surgical group, and relapse group shared a similar pattern to that of direct costs.

This study has the following limitations:

(I) The database we utilized did not cover information from provincial hospitals, making the study population less representative. For example, we might not have included enough patients who suffered from unusually severe symptoms.

(II) This study was based on EMR data directly from hospitals. Not all patients have a follow-up visit record. This might be caused by the fact that instead of going to visit a doctor regularly, some patients with stable symptoms might choose pharmacies for regular drug purchasing. Thus, a lack of data on pharmacy visits adds to the challenges of analyzing patients' treatment patterns.

(III) Limited by a small sample size, we could only identify few patients who underwent relapse. Statistical associations were hard to establish with the available sample size.

(IV) The cutoff value of blood EOS\% remains poorly defined. Furthermore, eosinophilia exhibits significant geographical and ethnic differences. Various cutoff values for blood EOS\% percentage have been proposed by researchers worldwide (22-24). The database we utilized typically covered patients who lived in Jinan City, Shandong Province, China. The patient population may not be representative of real samples across China.

(V) Further investigations and validations using a larger cohort is recommended, together with an analysis of gender differences.

\section{Conclusions}

This study explored the demographics, comorbidities, prescriptions, and disease burden of CRSwNP patients, CRSwNP patients who underwent ESS, and patients who relapsed after ESS. The results indicated that CRSwNP patients have a higher chance of having asthma or allergic rhinitis as comorbidities. Treatments for patients who have these underlying comorbidities should be enforced. In addition, the results showed that compared with nonsurgical patients, patients who underwent ESS typically had considerably higher costs. Also, the loss of working days of surgical patients was approximately 2.4 times that of nonsurgical patients. Moreover, surgical patients might relapse in the future, further leading to an increased disease burden. Therefore, effective drugs that can replace surgery need to be developed in the near future. They would not only relieve disease-related and ESS-related pain, but also reduce 
the disease burden significantly.

\section{Acknowledgments}

Funding: None.

\section{Footnote}

Reporting Checklist: The authors have completed the STROBE reporting checklist. Available at https://atm. amegroups.com/article/view/10.21037/atm-22-65/rc

Data Sharing Statement: Available at https://atm.amegroups. com/article/view/10.21037/atm-22-65/dss

Conflicts of Interest: All authors have completed the ICMJE uniform disclosure form (available at https://atm. amegroups.com/article/view/10.21037/atm-22-65/coif). HL is from Shanghai Palan DataRx Co., Ltd. The other authors have no conflicts of interest to declare.

Ethical Statement: The authors are accountable for all aspects of the work in ensuring that questions related to the accuracy or integrity of any part of the work are appropriately investigated and resolved. This study was approved by the Ethics Committee of Jinan Central Hospital (approval number: 2020-032-02), and patient consents were waived due to retrospective study design. All procedures in this study involving human participants were conducted in accordance with the Declaration of Helsinki (as revised in 2013).

Open Access Statement: This is an Open Access article distributed in accordance with the Creative Commons Attribution-NonCommercial-NoDerivs 4.0 International License (CC BY-NC-ND 4.0), which permits the noncommercial replication and distribution of the article with the strict proviso that no changes or edits are made and the original work is properly cited (including links to both the formal publication through the relevant DOI and the license). See: https://creativecommons.org/licenses/by-nc-nd/4.0/.

\section{References}

1. Fokkens WJ, Lund VJ, Mullol J, et al. European Position Paper on Rhinosinusitis and Nasal Polyps 2012. Rhinol Suppl 2012;23:3 p preceding table of contents, 1-298.

2. Shi JB, Fu QL, Zhang H, et al. Epidemiology of chronic rhinosinusitis: results from a cross-sectional survey in seven Chinese cities. Allergy 2015;70:533-9.

3. Stevens WW, Schleimer RP, Kern RC. Chronic Rhinosinusitis with Nasal Polyps. J Allergy Clin Immunol Pract 2016;4:565-72.

4. Cao PP, Li HB, Wang BF, et al. Distinct immunopathologic characteristics of various types of chronic rhinosinusitis in adult Chinese. J Allergy Clin Immunol 2009;124:478-84, 484.e1-2.

5. Vlaminck S, Vauterin T, Hellings PW, et al. The importance of local eosinophilia in the surgical outcome of chronic rhinosinusitis: a 3-year prospective observational study. Am J Rhinol Allergy 2014;28:260-4.

6. Lou H, Zhang N, Bachert C, et al. Highlights of eosinophilic chronic rhinosinusitis with nasal polyps in definition, prognosis, and advancement. Int Forum Allergy Rhinol 2018;8:1218-25.

7. Tan BK, Chandra RK, Pollak J, et al. Incidence and associated premorbid diagnoses of patients with chronic rhinosinusitis. J Allergy Clin Immunol 2013;131:1350-60.

8. Peters AT, Spector S, Hsu J, et al. Diagnosis and management of rhinosinusitis: a practice parameter update. Ann Allergy Asthma Immunol 2014;113:347-85.

9. Lund VJ, Flood J, Sykes AP, et al. Effect of fluticasone in severe polyposis. Arch Otolaryngol Head Neck Surg 1998;124:513-8.

10. Bachert C, Luo Z, Phillippe G. Current and future treatment options for adult chronic rhinosinusitis: focus on nasal polyposis. J Allergy Clin Immun 2015;136:1431-40.

11. Lou H, Wang CS, Zhang L. Endotype-driven precision medicine in chronic rhinosinusitis. Expert Rev Clin Immunol 2019;15:1171-83.

12. Bhattacharyya N, Villeneuve S, Joish VN, et al. Cost burden and resource utilization in patients with chronic rhinosinusitis and nasal polyps. Laryngoscope 2019;129:1969-75.

13. Zhang L, Zhang Y, Gao Y, et al. Long-term outcomes of different endoscopic sinus surgery in recurrent chronic rhinosinusitis with nasal polyps and asthma. Rhinology 2020;58:126-35.

14. Ishitoya J, Sakuma Y, Tsukuda M. Eosinophilic chronic rhinosinusitis in Japan. Allergol Int 2010;59:239-45.

15. Bachert C, Bhattacharyya N, Desrosiers M, et al. Burden of Disease in Chronic Rhinosinusitis with Nasal Polyps. J Asthma Allergy 2021;14:127-34.

16. Hu Y, Cao PP, Liang GT, et al. Diagnostic significance of blood eosinophil count in eosinophilic chronic rhinosinusitis with nasal polyps in Chinese adults. 
Laryngoscope 2012;122:498-503.

17. Grigoreas C, Vourdas D, Petalas K, et al. Nasal polyps in patients with rhinitis and asthma. Allergy Asthma Proc 2002;23:169-74.

18. Caulley L, Thavorn K, Rudmik L, et al. Direct costs of adult chronic rhinosinusitis by using 4 methods of estimation: Results of the US Medical Expenditure Panel Survey. J Allergy Clin Immunol 2015;136:1517-22.

19. Rudmik L, Schlosser RJ, Smith TL, et al. Impact of topical nasal steroid therapy on symptoms of nasal polyposis: a meta-analysis. Laryngoscope 2012;122:1431-7.

20. Poetker DM, Jakubowski LA, Lal D, et al. Oral corticosteroids in the management of adult chronic rhinosinusitis with and without nasal polyps: an evidencebased review with recommendations. Int Forum Allergy Rhinol 2013;3:104-20.

Cite this article as: Zhao Q, Yu L, Jin P, Ma W, Duan S, Luo H. A comprehensive investigation of the demographics, treatments, comorbidities, and disease burden of chronic rhinosinusitis with nasal polyposis patients: a descriptive analysis. Ann Transl Med 2022;10(3):150. doi: 10.21037/atm-22-65
21. Meng Y, Yan B, Wang Y, et al. Diagnosis and management of nonallergic rhinitis with eosinophilia syndrome using cystatin SN together with symptoms. World Allergy Organ J 2020;13:100134.

22. Kim JW, Hong SL, Kim YK, et al. Histological and immunological features of non-eosinophilic nasal polyps. Otolaryngol Head Neck Surg 2007;137:925-30.

23. Jankowski R, Bouchoua F, Coffinet L, et al. Clinical factors influencing the eosinophil infiltration of nasal polyps. Rhinology 2002;40:173-8.

24. Bonfils P, Badoual C, Bonfils NA, et al. Eosinophil infiltration of nasal polyps in patients with nasal polyposis: role in clinical evolution after medical and surgical treatment. J Laryngol Otol 2009;123:509-16.

(English Language Editor: C. Betlazar-Maseh) 